\title{
TRANSPORTE AUTOMOTIVO E DIMENSÕES SOCIOESPACIAIS DO CAPITALISMO NO SÉCULO XX
}

\author{
Ralfo Matos
}

Amélia Maria

As reestruturações econômicas e socioespaciais do século XX fizeram parte de processos de mudanças de larga duração, nos quais inclui-se a ampliação dos mercados mundializados e a configuração da dicotomia países capitalistas centrais e periféricos. Tudo isso veio provocar impactos profundos na mobilidade das pessoas e na própria urbanização e localização de atividades econômicas.

Ainda nas primeiras décadas do século, o fordismo enquanto modo de regulação ${ }^{1}$ e de produção evoluía dentro de duas lógicas: a da produção e a do consumo. Sob qualquer uma delas pode-se entender parte das mudanças econômicas e socioespaciais protagonizadas pelo avanço da indústria automobilística, notadamente quando as dimensões tecnológica e cultural são examinadas ao lado dos processos de urbanização e expansão demográfica.

De fato, o transporte rodoviário não surgiria sem uma série de inovações tecnológicas que se acumularam desde a segunda metade do século XIX. O paradigma automotivo, além de multiplicar as possibilidades de deslocamentos, cumpriu uma série de funções que fizeram crescer vertiginosamente o consumo de espaços públicos, em um processo de concorrência com o transporte ferroviário que produziria uma série de reflexos nas sociedades modernas.

Nas primeiras décadas do século $\mathrm{XX}$ os processos de urbanização tornaram-se mais densos e as novas tecnologias propiciaram uma expansão inusitada dos assentamentos humanos, em meio a uma série de novidades com a modernização das cidades e dos costumes. A chamada revolução dos transportes e comunicações encurtou o tempo e as

\footnotetext{
${ }^{1}$ Modo de regulação: "O regime de acumulação não flutua, não é desencarnado, no mundo etéreo dos esquemas de reprodução. Para que este ou aquele esquema se realize, e se reproduza de forma durável, é preciso que formas institucionais, procedimentos e hábitos - agindo como forças coercitivas ou indutoras - conduzam os agentes privados a obedecerem a tais esquemas." (Lipietz, 1984, p. 305).
}

Cadernos do Leste

Artigos Cientificos

Belo Horizonte, Edição Especial, 2000 a 2008 
distâncias, fez surgir grandes áreas urbanas e favoreceu o aumento da capacidade de produção de novos bens e serviços em níveis inéditos. Surgia a produção em massa.

\section{1- O ADVENTO DO FORDISMO E SUA DISSEMINAÇÃO PELO MUNDO}

Em 1903, em Detroit (EUA), foi criada a Ford Motor Company, com Henry Ford como vice-presidente e engenheiro-chefe. Cinco anos depois, realiza-se o lançamento do Modelo Ford T, invariavelmente de cor preta, pois a indústria química encontrava-se em processo de definição de pigmentos. Era, na verdade, o primeiro a sair de uma linha de montagem de uma fábrica de automóvel. ${ }^{2} 1913$ marca o início de fato da disseminação dos impactos da nova indústria, quando, nos Estados Unidos, o "Modelo T", apelidado de tin lizzie (lata barata), foi colocado ao alcance das pessoas de renda média. A redução dos custos de produção e os incrementos de produtividade que as inovações técnicas incorporavam por meio das linhas de montagem não tinham paralelo na história.

A partir de 1914, essas novidades gradativamente penetram no setor automotivo, indo muito além do dia de oito horas e cinco dólares como recompensa para os trabalhadores da linha automática de montagem de carros como formulara Ford. O salário de cinco dólares/dia teve impacto em nível mundial, já que era praticamente o dobro do que se praticava na indústria americana. A ideia do dia de oito horas e cinco dólares incluía não só a disciplina do trabalhador na linha de montagem de alta produtividade, mas também revelava a intenção de dar aos trabalhadores renda e tempo de folga, para que assim se tornassem consumidores dos produtos que as corporações estavam por fabricar em quantidades cada vez maiores.

A própria explanação detalhada de Henry Ford, feita em 1926, sobre as características fundamentais do processo por ele implementado e sobre os primeiros passos da linha de montagem, enriquece o entendimento desse momento (ver Neto, 1991, p. 47):

2 O "modelo A" foi o primeiro carro a ser oferecido pela Ford Motor Company, em junho de 1903. A produção continuou oferecendo vários outros modelos, até chegar à pré-produção do "Modelo T", em 1908.

Cadernos do Leste

Artigos Cientificos

Belo Horizonte, Edição Especial, 2000 a 2008 
"O carro Ford consta de cinco mil peças, contando parafusos e porcas. Algumas bastante volumosas, e outras tão pequenas como as peças de um relógio. Quando montamos os primeiros carros o sistema consistia em serem as peças trazidas manualmente à medida das necessidades, tal como na construção de uma casa. Depois, ao iniciarmos a construção de peças, vimos que era necessário destinar uma seção especial da usina para o fabrico de cada uma delas, mas em regra um só operário fazia todas as operações exigidas por uma pequena peça. $O$ aumento rápido da produção nos obrigou a pensar num sistema no qual um operário não estorvasse outro. Operários mal dirigidos gastam mais tempo a correr atrás do material e da ferramenta do que a trabalhar e ganham pouco, porque isso de correr não constitui ocupação remuneradora. Nosso primeiro passo no aperfeiçoamento da montagem consistiu em trazer o trabalho ao operário em vez de levar o operário ao trabalho. Hoje todas as operações se inspiram no princípio de que nenhum operário deve ter mais que um passo a dar; nenhum operário deve ter que abaixar-se."

Os princípios que regeriam a linha de montagem seriam assim enumerados:

“ $1^{\circ}$ ) Trabalhadores e ferramentas devem ser dispostos na ordem natural da operação, de modo que cada componente tenha a menor distância possível a percorrer da primeira à última fase; $2^{\circ}$ ) Empregar planos inclinados ou aparelhos concebidos de modo que o operário sempre ponha no mesmo lugar a peça que terminou de trabalhar, indo ela à mão do operário imediato por força do seu próprio peso sempre que isto for possível; $3^{\circ}$ ) Usar uma rede de deslizadeiras por meio das quais as peças a montar se distribuam a distâncias convenientes.

Como resultado reduzir-se-iam drasticamente os movimentos dos operários no interior da fábrica, com a otimização dos gestos, atitudes e movimentos do operariado no novo processo produtivo. Nas palavras de Ford:

"Tudo se move em nossas oficinas. Isto, suspenso por correntes, indo ter ao ponto de montagem na ordem que lhe é designada. Aquilo, deslizando em planos movediços, ou arrastado pela lei da gravidade. O princípio geral é que nada deve ser carregado, mas tudo vir por si. Os materiais são trazidos em vagonetes ou reboques puxados por chassis Ford, suficientemente móveis e rápidos para deslizarem em todos os sentidos. Nenhum operário necessita carregar ou levantar qualquer coisa. Isso faz parte de um serviço distinto - o serviço de transporte. O princípio é que um operário não deve ser constrangido à precipitação: deve dispor do tempo exato, sem um segundo a mais nem um segundo a menos para executar a sua operação."

Cadernos do Leste

Artigos Científicos

Belo Horizonte, Edição Especial, 2000 a 2008 
A introdução da linha de montagem obrigava o trabalhador a adaptar-se ao ritmo da produção e não o contrário. Surgia a especialização de cada operário em tarefas repetitivas e monótonas. Instaurava-se a "massificação do proletariado" no interior do chamado compromisso fordista. ${ }^{3}$

O princípio fordista de organização industrial requeria, desde os anos 20, a utilização de técnicas de administração associadas com uma visão de mercado calcada nas tecnologias que favoreceram o aumento da produção e o barateamento dos custos.

"O fordismo é um claro exemplo da tese marxista de que a divisão técnica de trabalho é determinada pela intensificação da divisão social do trabalho. Caracteriza um novo estado de regulação do capitalismo e do regime de acumulação intensiva, no qual a classe capitalista espera controlar a reprodução global da força de trabalho assalariada, através da íntima articulação das relações de produção das mercadorias, por meio das quais os trabalhadores assalariados adquirem seus meios de consumo. O fordismo é, pois, o princípio de uma articulação do processo de produção e do modo de consumo, que instaura a produção em massa, chave da universalização do trabalho assalariado" (Aglietta, 1976, p. 93-94).

Se por um lado o termo fordismo é utilizado para designar as reconfigurações impostas aos processos produtivos que culminavam com a sua subordinação ao capital e redinamização do desenvolvimento do capitalismo, por outro lado, o compromisso fordista transformou profundamente a própria condição proletária em diversos aspectos (Bihr, 1999, p. 53). E, assim, mais do que uma simples maneira de aumentar a produção e a produtividade do operário trabalhador, o fordismo também se tornou, posteriormente, um modelo de regulação social, que tinha o Estado do "Welfare State" como seu principal avalista."

\footnotetext{
${ }^{3}$ Bihr (1991) afirma ser impossível dar conta das especificidades nacionais do compromisso fordista, tanto no que se refere às condições de estabelecimento (ligadas às especificidades das histórias nacionais), quanto às suas implicações e consequiências sociopolíticas. No tocante ao proletariado, esse compromisso pode ser comparado a uma espécie de imensa barganha, pelo qual renunciou-se "à aventura histórica em troca da garantia de sua seguridade social".

${ }^{4}$ Ford queria assegurar que os trabalhadores soubessem como gastar seu dinheiro adequadamente e, assim, enviou batalhões de assistentes sociais aos lares de seus empregados, em grande medida imigrantes, mais motivados à produção em linha de montagem, para garantir a conduta moral, a vida familiar e a capacidade de consumo, correspondendo às necessidades e expectativas da corporação (Harvey, 1993, p. 122). À genialidade de Ford incorporava-se o incremento à capacidade de produção de um lado, e, de outro, complementava-se com a perspectiva clara de atrair os trabalhadores ao consumo. Era preciso formar consumidores. Capital e trabalho, produção e consumo eram os grandes pilares para a explosão do capitalismo. E o fordismo, com suas ferramentas de organização industrial, fixava alguns eixos desse modelo de desenvolvimento econômico.
}

Cadernos do Leste

Artigos Cientificos

Belo Horizonte, Edição Especial, 2000 a 2008 
Antes de Ford, parte dessas inovações tecnológicas e organizacionais não era estranha à forma corporativa de organização de negócios adotada pelas estradas de ferro, notadamente após as fusões e formação de trustes e cartéis no final do século XIX (Harvey, 1993). Antes dele, Taylor já se detivera nos problemas referentes à eficiência do trabalho humano nas fábricas, sugerindo uma série de medidas para reduzir os "tempos mortos" nas ações e gestos de cada trabalhador. O próprio Marx já vislumbrara determinadas tendências do desenvolvimento do capitalismo industrial quando observava que "se na manufatura o isolamento dos processos diferenciados é um princípio ditado pela própria divisão do trabalho, na fábrica já desenvolvida impera o princípio da continuidade dos processos específicos”. (Marx, 1973).

Ford, basicamente, procura solucionar esse problema imanente à produção manual, superado pela maquinaria, ao "trazer o trabalho ao operário em vez de levar o operário ao trabalho", permitindo, dessa forma, que "nenhum operário necessite carregar ou levantar qualquer coisa". Dessa forma, o trabalho morto introduzido por Ford restringe-se ao que ele mesmo chamou de o serviço de transporte. Todas as tarefas de manutenção são assumidas pelo maquinismo: comboios, cintas transportadoras, chassis móveis (Neto, 1991).

Com as formulações de Taylor, esta complexidade acerca dos ritmos e das formas de produção começou a ser melhor compreendida. Vários analistas econômicos e mesmo alguns homens de negócio — relutantemente, perceberam a idéia de que o "progresso" capitalista não era inesgotável como haviam imaginado. Existiam sérias ameaças ao processo. As pressões das organizações sindicais, bem como a consciência de que as nações, pelo menos as mais desenvolvidas, estavam se tornando competitivas no mercado mundial, fizeram com que as empresas internalizassem as inovações tecnológicas e a administração científica de Taylor. A grande preocupação era a manutenção de uma taxa de crescimento segura e intermitente, incluindo-se a diminuição dos preços e a conseqüente redução dos custos de produção. Nesse momento, o capitalismo se apóia no fordismo, que "surge" como uma revolução tecnológica sem precedentes.

A distinção entre o fordismo e o taylorismo revela-se no que havia de especial em Ford:

Cadernos do Leste

Artigos Científicos

Belo Horizonte, Edição Especial, 2000 a 2008 
“...a sua visão, seu reconhecimento explícito de que a produção de massa significava consumo de massa, um novo sistema de reprodução da força de trabalho, uma nova política de controle e gerência do trabalho, uma nova estética e uma nova psicologia, em suma, um novo tipo de sociedade democrática, racionalizada, modernista e populista" (Harvey, 1993, p. 121).

Portanto, o fordismo, enquanto uma forma desenvolvida do taylorismo, caracteriza verdadeiramente um desenvolvimento da manufatura. Certamente, os processos mecanizados de trabalho impulsionaram o crescimento vertiginoso da indústria automobilística e contribuíram, inclusive, para reconfigurar os espaços públicos e privados em cidades e regiões. Espaços que incorporavam novas culturas e grandes mercados de consumo, a partir dos quais se instalava a grande indústria do século XX e que iria assistir a uma das mais dramáticas disputas entre segmentos da indústria dos transportes: de um lado o que representava o modal ferroviário, de outro lado o que viria conformar o chamado "rodoviarismo".

\section{2- DA PRIMEIRA GUERRA MUNDIAL AO NEW DEAL}

A economia mundial mantinha seu eixo mais dinâmico na Europa até o quarto decênio do século XX. Inglaterra, França e Alemanha centralizavam as decisões econômicas e financeiras, controlavam mercados consumidores e monopolizavam fontes de matéria prima, como no caso da "borracha", ditando preços e prazos. A libra esterlina era a moeda de troca internacional.

No início do século XX, crises, conflitos, guerras e decisões políticas acabaram por envolver esses países num confronto mundial que, praticamente, pôs fim à hegemonia econômica europeia, com o advento dos EUA como potência internacional.

Os EUA de fato conviviam com altos níveis de prosperidade desde a década de 20, apoiada em um forte liberalismo e forte crescimento da produção industrial. Efetivamente, desde 1922, quando França e Inglaterra saldaram suas dívidas com os EUA, os americanos experimentaram um período de espetacular expansão industrial, incrementado, principalmente, pelo setor de bens de consumo. A compra a crédito passou a ser estimulada, 
e dessa forma, rapidamente todos desejavam adquirir um carro, um rádio e outros bens. Muitos conseguiam obtê-los diante das facilidades que lhes eram oferecidas e essa forma de vida, que viria levar ao mundo inteiro os signos da modernidade e bem-estar do alto capitalismo, ficou conhecida como american way of life (Hobsbawm, 2000).

Contudo, a grande depressão iniciada em 1929 e com efeitos até pelo menos 1934, foi responsável pelo fechamento de indústrias, debilitamento de amplos setores da economia mundial e expansão dramática do desemprego. Foi a mais longa e profunda recessão econômica experimentada pelos países capitalistas e abriu espaço para um inédito intervencionismo estatal, como nos EUA da década de 30 sob o governo Roosevelt.

\section{A Crise de 1929}

Com o fim da Primeira Guerra Mundial, ao lado da emergência da URSS (União das Repúblicas Socialistas Soviéticas), os EUA se tornaram um exemplo notável, pelo fato de ter sido o único país capitalista que não conheceu uma crise logo depois da guerra. Ao contrário, vivenciou um período de abundância sem paralelo, até estourar o crack da Bolsa de New York, em 1929.5

Aparentemente, uma das razões da crise pode ser atribuída ao fenômeno especulativo que promoveu a grande alta no mercado de valores, por volta de 1929, o que atraiu à Bolsa cerca de 10 milhões de investidores. Convém observar, que nessa época do "milagre americano", fatores como a debilidade da agricultura, o desemprego tecnológico ${ }^{6}$ e a má

\footnotetext{
${ }^{5}$ Quinta-feira negra, data em que 16 milhões de títulos colocados à venda não encontraram compradores. Muitos entendiam que a crise seria passageira. O presidente norte-americano, Hoover, afirmava tratar-se de uma simples recessão: 'comprem, a prosperidade está na próxima esquina'. Faulkner (1956) e Rybczynski (1995) afirmam que o primeiro sinal de que alguma mudança estava no ar foi dado em 11 de novembro de 1929, com a falência da Companhia de Transportes de Plattsburgh, a duas semanas da quebra do mercado de ações de Wall Street. Esse evento não era, obviamente, a causa da crise, mas sim, indicava que a companhia vinha perdendo muito dinheiro nos últimos nove anos, ocasionando um aumento nos custos de operação da linha, o que parecia colaborar para pôr em check o sistema de transportes sobre trilhos. Enquanto isso, as pessoas andavam cada vez menos de bonde e mais de carro, o que promovia novas demandas nas áreas urbanas.

${ }^{6}$ Nas cidades, com a mecanização, muitos trabalhadores foram dispensados, criando-se um grande exército de reserva de mão-de-obra e de desempregados. Conseqüentemente, esses trabalhadores da cidade, juntamente com os trabalhadores do campo deixaram de consumir, o que fazia as vendas e o lucro despencarem. Diante dessa situação, os grandes
}

Cadernos do Leste

Artigos Cientificos

Belo Horizonte, Edição Especial, 2000 a 2008 
distribuição de renda ocasionavam grande redução na taxa de formação do capital. Como os salários cresciam menos que a produtividade, evidenciava-se a "incapacidade aquisitiva dos trabalhadores para absorver a produção. E, em conseqüência, ocorria a superprodução" (Faulkner, 1956).

No começo de 1930, novo pânico ocorreu: os bancos norte-americanos deixaram de abrir linhas de crédito para os países estrangeiros e passaram a repatriar os capitais que tinham investido no exterior. Essa medida repercutiu fortemente na Europa, a ponto de instalar uma crise industrial e financeira sem precedentes ao lado da expansão do desemprego em todo o mundo. Em 1929, estima-se em 10 milhões os desempregados e, em 1932, 30 milhões.

A crise afetou todos os setores, inclusive o setor de transporte. O processo de motorização diminuiu seu ímpeto de crescimento. O mundo das décadas seguintes seria irreversivelmente diferente, e certamente seria incompreensível sem o entendimento da profundidade e abrangência da grande depressão resultante da crise de 1929. Cada país a seu modo, procurou maneiras diferenciadas de superar a crise, sempre com a marcante presença do Estado no mundo econômico.

\section{O New Deal}

Em 1932, o Partido Democrata elegeu Franklin Delano Roosevelt (1932-1945), ${ }^{7}$ cuja plataforma eleitoral baseava-se em um programa de recuperação econômico-social do país denominado New Deal (novo acordo). Sua implementação iniciou-se a partir de 1933, mediante forte participação do Estado. O velho liberalismo cedia lugar a uma economia dirigida pelo governo.

O New Deal introduziu, entre outros benefícios, o subsídio ao desemprego e projetos de obras públicas. Roosevelt foi fortemente influenciado pelas ideias de Keynes, que defendia uma política antidesemprego patrocinada pelo governo, o que deu origem a chamado estado

empresários passaram a especular na Bolsa de Valores, outorgando às suas ações valores fictícios, muito mais altos do que os reais.

${ }^{7}$ Quando assumiu a presidência, a crise econômico-social havia atingido seu ápice: mais de 25\% da população ativa estava desempregada; as atividades comerciais decresceram mais de $60 \%$ e, aproximadamente, 1400 bancos haviam falido.

Cadernos do Leste

Artigos Cientificos

Belo Horizonte, Edição Especial, 2000 a 2008 
do bem-estar social (Welfare State), um sistema que garantia saúde, educação e aposentadoria a todos. Recuperação e reforma foram os objetivos da nova política econômica, o que incluía o fortalecimento de setores debilitados, como a agricultura e a infraestrutura. Ações de caráter humanitário foram desenvolvidas nos programas de atenção aos idosos, desempregados e ajuda aos necessitados, ao lado de investimentos em obras públicas, combate ao desemprego e aumento no poder de compra da população, o que incluía as empresas de negócios e os líderes empresariais (Cf. Galbraith, 2000).

Conforme destaca Faulkner (1956), podia-se distinguir duas etapas nos programas governamentais. Entre 1933 a 1935, um primeiro New Deal dirigiu-se à recuperação econômica através de uma estreita cooperação com as empresas privadas. Entre 1935 a 1939 , um segundo voltava-se à recuperação permanente, mediante outorga de poder aquisitivo aos grupos menos privilegiados e ampliação da segurança social.

Nesse período, também surgiu uma acirrada oposição a Roosevelt, em face da magnitude das intervenções e dos projetos deflagrados pelo governo com base em recursos federais, vários deles bem articulados a objetivos sociais. A TVA (Tennessee Valley Authority), inegavelmente incorporava o mais importante empreendimento do planejamento inscrito no New Deal, boa parte dele relativamente próximo às idéias radicais da época, tanto no âmbito da associação RPAA $^{8}$ quanto dos regionalistas sulinos.

Berman (1994) observa que os projetos do New Deal foram primeiramente concebidos para criar atividade econômica, fomentar o consumo e estimular o setor privado. A intenção era trazer milhões de desempregados de volta ao trabalho e estimular a paz social. Posteriormente, acelerar-se-ia a modernização das economias das regiões nas quais seriam executados os projetos, ampliariam o significado do "público, com a demonstração dos benefícios advindos das obras públicas".

\footnotetext{
${ }^{8}$ REGIONAL PLANNING ASSOCIATION OF AMERICA (RPAA) - surgiu de uma associação casual de Mumford, Stein, Benton Mackaye e Charles Harris Whitaker, por volta de 1923. Quando tinha apenas 22 anos, Mumford redigira o trabalho "As civilizações-jardim preparam-se para uma nova época", aparentemente inédito, sobre a descentralização industrial e as cidades-jardim. (Hall, 1988). Em 1923, durante visita de Geddes a New York, o grupo adotou um programa que continha propostas inovadoras: criação de cidades-jardim dentro de um esquema regional; desenvolvimento de relações com os planejadores britânicos, sobretudo com Geddes.
}

Cadernos do Leste

Artigos Cientificos

Belo Horizonte, Edição Especial, 2000 a 2008 
O New Deal propiciou a utilização de novas tecnologias e disseminou a promessa de um futuro promissor, um novo tempo, não apenas para poucos privilegiados, mas para o conjunto da população. No entanto, a burocracia do New Deal tornou-se muito pesada.

Robert Moses foi o grande colaborador do presidente Roosevelt e compreendia o valor das crescentes obras governamentais como espetáculo público. Foi aclamado pela obras de recuperação de 1700 parques de New York, prestígio de que se valeu para algo que a seus olhos valia muito mais que os parques: o sistema de rodovias, avenidas arborizadas e pontes que entrelaçariam a área metropolitana. O conhecido projeto Triborough era composto por uma rede colossal de pontes, acessos e avenidas que uniria Manhattam, o Bronx e Westchester a Queen e a Long Island, criando um conjunto de novos e espetaculares acessos à cidade, que exibiam o esplendor de Manhattam de muitos ângulos inéditos. Esses projetos marcaram profundamente a cidade de New York e alimentaram toda uma geração de fantasias urbanas. Para implementá-los, foram realizadas uma série de incursões drásticas na rede urbana de Manhattam. (Berman, 1994).

\section{3- O AUTOMOBILISMO E O FORDISMO-KEYNESIANISMO NA EXPANSÃO DO PÓS-GUERRA}

Entre 1920 e final da década de 30, a Ford consumia um quarto da produção mundial de borracha. Insatisfeito, há tempos, com as condições que o monopólio inglês impunha ao mercado mundial, o que contribuía para elevar os preços dos carros, Henry Ford financiou custosas e malogradas pesquisas para produzir borracha artificialmente, pois pretendia converter-se no maior produtor do mundo. Envidou esforços em busca de um lugar apropriado no Panamá, Colômbia e algumas zonas da Ásia e da África para estabelecer uma gigantesca plantação. Ao final optou pela Amazônia, onde comprara "milhões de hectares para produzir tanta borracha quantos fossem os pneus necessários para a indústria automobilística" ${ }^{\prime 3}$.

\footnotetext{
${ }^{15}$ A previsão era de produzir toneladas de látex/ano até 1956, caracterizando o que Ford tinha declarado no Congresso da União, "a colonização mais ambiciosa da Amazônia". Uma cidade industrial é construída à margem do Rio Tapajós (Sguiglia,1997).
}

Cadernos do Leste

Artigos Científicos

Belo Horizonte, Edição Especial, 2000 a 2008 
De todo o modo, a indústria automotiva tornara-se um sustentáculo da expansão econômica americana, inclusive como setor estratégico no ciclo de recuperação após vencida a grande depressão dos anos de 1930. A produção de carros americana passara de uma pequena produção artesanal de pouco mais de quatro mil veículos em 1900 para mais de 5,3 milhões em 1929. Durante muito tempo, o setor foi dominado pelos Big Three: Ford, General Motors e Chrysler (ver Quadro 1), até que, gradativamente, a General Motors, tornase a maior empresa do setor. ${ }^{30}$

No resto do mundo, inspirados no exemplo da recuperação americana e no New Deal, vários países capitalistas se voltaram para a redefinição das atribuições do Estado. A crise de 29 mostrara a importância da demanda efetiva de produtos industriais. De outra parte, os estudos de Keynes tornaram-se paradigmáticos, porque viam o Estado como um promotor de estratégias administrativas e científicas, com vistas à estabilização do capitalismo e manutenção do crescimento econômico. Enfim, a nova reconfiguração e uso dos poderes do Estado se consolidam depois de 1945 (Harvey, 1993, p. 125). Essa mudança levou o fordismo à maturidade como regime de acumulação plenamente desenvolvido, constituindo a base de um longo período de expansão que se manteve mais ou menos intacto até 1973.

Parte do sucesso do fordismo no pós-guerra pode ser explicado pela ascensão de indústrias tecnologicamente avançadas, localizadas em regiões estratégicas que rapidamente ganharam destaque na economia mundial (entre elas o Meio Oeste dos EUA). Os exemplos necessariamente passam pelas indústrias automobilística; de construção naval e equipamentos de transporte; de construção civil e construção pesada; de produção de aço, produtos petroquímicos e borracha.

Por outro lado, uma outra frente, claramente associada aos setores supracitados, que também explica a recuperação da demanda, estava assentada na

\footnotetext{
${ }^{14}$ Alfred Sloan, da GM, conseguiu habilmente resolver o impasse que atormentou Ford, ao dividir e implantar um rígido sistema de controle em sua empresa. Além disso, "criou uma linha de cinco modelos básicos de veículos para atender melhor o mercado", diferentemente da Ford, que tinha apenas o modelo T, além de estruturar, na GM, funções na área de finanças e marketing, estabelecia "uma forma de convivência do sistema de produção em massa com a necessidade de gerenciar uma organização gigantesca e multifacetada".
}

Cadernos do Leste

Artigos Cientificos

Belo Horizonte, Edição Especial, 2000 a 2008 
"reconstrução patrocinada pelo Estado de economias devastadas pela guerra, na suburbanização (particularmente nos Estados Unidos), na renovação urbana, na expansão geográfica dos sistemas de transporte e comunicações e no desenvolvimento infra-estrutural dentro e fora do mundo capitalista avançado. Coordenadas por centros financeiros interligados, tendo como ápice da hierarquia os Estados Unidos e Nova Iorque, essas regiões-chave da economia mundial absorviam grandes quantidades de matérias-primas do resto do mundo não-comunista e buscavam dominar um mercado mundial de massa crescentemente homogêneo com seus produtos" (Harvey, 1993, p. 125).

O fordismo, portanto foi muito além de um simples modelo produtivo que se baseava na utilização intensiva de tecnologia para incrementar a produtividade por trabalhador. A sua lógica é complexa, pois, produção em massa requeria consumo em massa, demanda segura, efetiva, o que deflagrou uma mudança drástica nos padrões de consumo e nas formas de vida da sociedade de então. O fordismo, aliado ao estado do bem-estar social que financiava a frente do consumo com políticas públicas, conseguiu resultados surpreendentes até a década de 1970, apesar das inúmeras crises e problemas estruturais inerentes ao próprio capitalismo.

A expansão continuada do pós-guerra vinculou-se a uma série de compromissos institucionais inscritos nos novos papeis assumidos pelos Estado. Os governos passaram a fornecer um complemento ao salário real dos trabalhadores, por meio de políticas públicas de seguridade social, assistência médica, seguro desemprego ou, ainda, mediante formas de controle, direto ou indireto, sobre os acordos salariais e direitos trabalhistas. Nos EUA, os sindicatos ganharam considerável poder na esfera da negociação coletiva nas indústrias de produção em massa do Meio-Oeste e do Nordeste, conquistaram e preservavam, inclusive, algum controle do chão das fábricas sobre questões associadas a segurança, promoções, salário mínimo e outras facetas da política social. (Harvey, 1993, p.128).

O fordismo-keynesianismo se mostrou vantajoso para as indústrias e países capitalistas avançados porque garantia o crescimento sustentado dos investimentos, e fazia aumentar a produtividade e a elevação dos lucros. A produção em massa exigia pesados investimentos em capital fixo, além de requerer, para sua estabilidade, demanda relativamente estável. Talvez por essas razões, é que essa forma de produção capitalista se difundiu por outras regiões do

Cadernos do Leste

Artigos Cientificos

Belo Horizonte, Edição Especial, 2000 a 2008 
mundo e muitos ramos de atividade, e introduziu mudanças significativas no comportamento do consumidor. Bens e serviços que eram restritos a uma minoria abastada tornaram-se acessíveis aos mercados de massa. ${ }^{9}$

Contudo, a difusão mundial do fordismo não se processou sob as mesmas condições dos países centrais, onde, afinal, havia um acordo tácito entre capital, trabalho e Estado. Nos países periféricos e em regiões pouco industrializadas, houve uma fortíssima taxa de exploração da mão-de-obra, que envolvia jornadas de trabalho, salários, aumento da intensidade do trabalho. Lipietz (1984) entende esse processo como a conjunção da acumulação intensiva e do crescimento de mercados de fordismo periférico (periférico porque as atribuições do trabalho, a proteção social e a produção mais qualificada continuavam nos países de centro).

O fordismo pode então explicar, em certa medida, as profundas mudanças que a indústria automobilística protagoniza no século XX? Sim, desde que se considere o consumo como estratégia maior da expansão capitalista. É interessante notar que os produtos mais claramente prováveis de serem desenvolvidos a partir da linha de montagem e produção em massa, eram, originalmente, aqueles utilizados pela maioria das pessoas à época (pequenos produtores, costureiros, alfaiates, funcionários do comércio), inclusive pequenas armas e munições. Artigos de grande porte não eram passíveis de produção em massa até mais ou menos 1920 devido às dificuldades técnicas, inclusive de organização industrial, além dos altos custos. Surpreendentemente, os americanos não só levaram a produção em massa a

\footnotetext{
${ }^{9}$ Segundo Harvey (1993), a disseminação mundial do fordismo só se deu após a II guerra, por dois principais impedimentos. Para começar, um dos participantes desse processo, o operariado, oferecia resistência à aceitação de um sistema de produção que se apoiava em longas horas de trabalho puramente rotinizado, que requeria poucas habilidades manuais, e o afastava do controle do projeto, ritmo e organização do processo produtivo. Os imigrantes, quase que exclusivamente utilizados por Ford no processo de produção, incorporaram a nova cultura, enquanto os americanos mantinham-se hostis. A segunda barreira importante a ser considerada, se traduzia nos modos e mecanismos de intervenção estatal, que somente se afirmaram após 1945, quando se impões a necessidade de se definir uma nova forma de regulamentação que a produção fordista sugeria. Ademais, parece ter sido também necessário acontecer o choque da depressão e o quase colapso do capitalismo na década de 30, para que as sociedades capitalistas percebessem a necessidade de mudança na forma e uso dos poderes do Estado. (Harvey, 1993).
}

Cadernos do Leste

Artigos Cientificos

Belo Horizonte, Edição Especial, 2000 a 2008 
produtos maiores, como o automóvel, ${ }^{33}$ bem como aumentaram seu nível de sofisticação, em relação a pigmentos industriais, novos dispositivos e tecnologias.

Durante décadas, o sistema criado por Ford e aperfeiçoado por Sloan, da General Motors, funcionou perfeitamente, e as empresas americanas dominaram o mercado de automóveis. Somente a partir de 1955, essa tendência começou a dar seus primeiros sinais de esgotamento. Surgiam grandes fabricantes na Europa que aplicavam os mesmos princípios, mas desenvolvendo veículos mais adaptados às condições do continente. Simultaneamente, aumentavam-se as reivindicações da força de trabalho, em torno de questões como salários e jornadas de trabalho.

Entre 1960 e 1970, alguns avanços relevantes são introduzidos no setor, provavelmente explicados pela busca de manutenção das taxas de lucro e do equilíbrio de poder por parte das corporações, o que acabou resultaria, a partir de 1965, na deslocalização da indústria de automóvel americana (Ford e a GM).

Não obstante as tentativas de resposta das grandes corporações, a crise do petróleo dos anos 70 aconteceu exatamente num momento de estagnação das indústrias européias e americanas. Nesse momento, a ascensão de novos concorrentes promove uma pressão sobre o modelo de produção em massa. A produção japonesa passou de 18.500 unidades em 1950, para 165 mil em 1960 e mais de 3,9 milhões em 1970.

Tão profundas e expressivas mudanças vieram alterar em profundidade as paisagens geográficas de regiões e países, particularmente nas grandes cidades. Soja (1993, p. 210-222) ao analisar o período, observa que fatores como a presença do Estado na economia, a produção em massa de automóveis (por empresas estatais, em muitos países), os transportes aéreos (em sua maioria dirigidos pelo Estado), a indústria petrolífera (maciçamente subsidiada, para alimentar a maior mobilidade física), a Construção Civil (fomentada por

\footnotetext{
${ }^{17}$ A era do automóvel, portanto, há muito chegara à América do Norte (Hobsbawn, 2000, p. 259). O combustível barato fazia do caminhão e do ônibus o grande meio de transporte na maior parte do ocidente, em torno de 1930. O modelo de produção em massa de Henry Ford, nos EUA, ampliara-se para novos tipos de produção: da construção de habitações à chamada junk food (o Mc Donald's foi uma típica história de sucesso financeiro no pós-guerra). No conforto doméstico, o que antes era luxo, tornou-se o padrão desejado, pelo menos nos países ricos: a geladeira, a lavadora de roupas automática, o telefone.
}

Cadernos do Leste

Artigos Científicos

Belo Horizonte, Edição Especial, 2000 a 2008 
programas governamentais de hipotecas e empréstimos) e a produção de bens de consumo duráveis (televisores, máquinas de lavar e outros bens que permitissem a maior privatização do consumo, antes mais coletivamente organizado) "lideraram a expansão econômica e contribuíram para grandes mudanças na forma urbana, especialmente através do processo concomitante de suburbanização". Esse momento histórico do século XX, de grande reestruturação econômica, urbana e social, coincide com o abandono ou ruptura com o transporte ferroviário.

Segundo vários autores, o modo de vida total, como marca do fordismo, ao ultrapassar o processo produtivo originário da indústria automobilística, fez surgir um vasto conjunto de atividades industriais que deu forma definitiva às sociedades de consumo de massa. Entretanto, a partir da crise de 1973, agravada pelo choque do petróleo, iniciou-se um processo de mudanças que, gradativamente iria fazer erodir o chamado compromisso fordista. As reestruturações prosseguiram e atingiram tanto empresas, quanto governos, o que fazia aflorar experiências que viriam representar os primeiros passos para um novo regime de acumulação - a chamada "acumulação flexível" - inteiramente associado a um sistema de regulamentação política e social específico. Harvey (1993, p. 140).

\section{4- O DECLÍNIO DAS FERROVIAS E A PREDOMINÂNCIA DO AUTOMÓVEL NO CAPITALISMO URBANO-INDUSTRIAL}

As estradas de ferro foram, sem dúvida, uma das inovações que serviu de sustentáculo à expansão capitalista na segunda metade do século XIX. ${ }^{34}$

\footnotetext{
${ }_{18}$ A partir de 1840, a construção de redes ferroviárias ocorre em quase toda a Europa e nos EUA e mesmo em outros lugares do mundo. "Em 1845, fora da Europa, o único país subdesenvolvido a possuir uma milha que fosse de estrada de ferro era Cuba." Por volta de 1875, Brasil, Argentina, Peru e Egito tinham perto de mil milhas ou mais de trilhos e, no mundo, havia "62 mil locomotivas, 112 mil vagões de passageiros [...] segundo as estimativas da época, 1.371 bilhão de
}

Cadernos do Leste

Artigos Cientificos

Belo Horizonte, Edição Especial, 2000 a 2008 
"As ferrovias eram os tendões de ferro que desenhavam em torno de si o capitalismo industrial. Naturalmente, a difusão de estradas de ferro através do globo era então sinônimo da difusão do capitalismo industrial.’(Ludd, 2004, p. 86).

Por meio delas reorganiza-se amplamente a localização da produção fabril, em face da abertura de novos acessos aos mercados nacional e internacional. Amparada pela capacidade das ferrovias em transportar rapidamente grandes quantidades de materiais através de grandes distâncias, a mecanização da produção se realizar como nunca. Para implementar essa mecanização, foram requisitadas grandes quantidades de aço e carvão para a construção, operação e manutenção das máquinas. As ferrovias sintetizavam a mecanização dos transportes, porquanto introduziam a regularidade mecânica da máquina e submetiam todos aos quadros de horários da ferrovia e à disciplina dos tempos precisos da partida e da chegada.

Com as ferrovias surgem núcleos suburbanos nas maiores cidades, enfileirados ao longo das estradas de ferro, descontínuos e polarizados pelas estações ferroviárias. Sem uma legislação que os protegesse, disseminavam-se segundo a lógica das paradas de quatro a oito quilômetros do trem de ferro. As moradias tinham que respeitar as distâncias percorridas a pé até a estação de passageiros, como mostravam os prospectos de propaganda. A partir de 1895, consolidam-se os "subúrbios ferroviários", com o transporte eletrificado (o bonde) e o subterrâneo" (Mumford, 1965, p. 641).

O subúrbio conformava áreas que se mantinham quase compactas, mas tendentes a se alongarem pelos corredores viários. Até uma certa época, a estação ferroviária e o deslocamento a pé controlaram o seu crescimento. A partir do momento em que o automóvel se generaliza nos E.U.A., desaparecia a escala pedestre do subúrbio, e, com ela, a maior parte de suas idiossincrasias. A mobilidade se expande com o automóvel. Os limites são ultrapassados e o subúrbio passa a fazer parte das fisionomias homogêneas das metrópoles. ${ }^{10}$

passageiros e 715 milhões de toneladas de mercadorias [...], nove vezes mais do que era transportado anualmente por via marítima [...] naquela década" (Hobsbawm, 2001, p.87-88).

${ }^{10}$ Mumford (1965, p. 644) afirma que "o automóvel tinha feito algo mais do que afastar os primeiros limites e destruir a escala pedestre". Promoveu, com as novas possibilidades de deslocamento, a duplicação paulatina do número de carros

Cadernos do Leste

Artigos Científicos

Belo Horizonte, Edição Especial, 2000 a 2008 
$\mathrm{Na}$ virada do século XIX para o XX, as estradas de ferro começaram a experimentar situações de crise, cuja solução viria acarretar o seu declínio e a ascensão da indústria automobilística. Já se afigurava claro uma espécie de corrida de obstáculos na direção da geração de riqueza nova em meio a extraordinárias taxas de lucro, mediante a redução do tempo de retorno dos investimentos. A indústria automobilística utilizou, desde o início, diversos mecanismos para colocar seu produto em condições de consumo, dentro de prazos que aumentassem os lucros e gerassem expansão dos negócios: um deles foi a adoção do princípio fordista de organização industrial já abordada anteriormente; outro foi a redução propriamente dita do tempo de circulação do capital exigia por meio de um transporte eficiente para as pessoas e mercadorias (Ludd, 2004, p. 86).

Contudo, não obstante as lógicas acima mencionadas, ainda assim, pode-se perguntar por que o transporte rodoviário foi tão preferido ao transporte ferroviário, sobretudo se considera-se que em termos econômicos, técnicos e ecológicos ele já havia avançado (inclusive com os metrôs) e gerava claros benefícios para as cidades e populações?

Uma das respostas passa pelas necessidades do grande capital em termos de inovações técnicas e transportes. O capital move-se por mecanismos que se orientam para a expansão. “É, essencialmente, a expansão ilimitada do valor [...] ele é a necessidade e o esforço para conseguir tal expansão indefinida. Ou seja, a economia deve expandir ou morrer!” (Ludd, 2004, p. 85). As estradas não cumprem simplesmente sua função de meio para transportar mercadorias. Aos donos do capital interessa a construção de mais estradas na medida em que a indústria automobilística tornava-se um fator-chave da acumulação. Assim sendo, ganha força a hipótese de que a ruptura com o modal ferroviário fora o resultado de confrontos econômicos e políticos que ocorreram nos Estados Unidos, a partir dos quais saíram vencedores os interesses das corporações vinculadas ao aço, borracha, cimento e petróleo. Há evidências de que os fatos até aqui analisados dão suporte a essas hipóteses. Afinal, se como afirma Jorge J. Okubaro (2001), "para a vida das pessoas, para o mercado de trabalho, para a

necessários por família, transformando a dona de casa suburbana americana, que detinha posses, em motorista de tempo integral.

Cadernos do Leste

Artigos Cientificos

Belo Horizonte, Edição Especial, 2000 a 2008 
organização da produção nas grandes unidades industriais, para a economia mundial, para a forma de vida nos ambientes urbanos e mesmo para a atividade rural, nada ainda supera a importância do automóvel", há menos de 100 anos atrás, somente os ricos podiam pagar nos EUA os 2.800 dólares que custavam os primeiros carros.

De todo modo, a indústria automobilística crescia vertiginosamente e se beneficiava de um amplo rol de avanços e aperfeiçoamentos que incidiram sobre a produção e processamento de derivados de petróleo, o que influiu decisivamente no desenvolvimento de conhecimentos nas áreas da química, física, biologia, economia e administração, engenharia, siderurgia, comunicações, transportes militar e civil. Os motores de combustão aperfeiçoamse e atingem os meios de transportes ferroviários e naval, por exemplo, forçam a padronização crescente dos produtos industriais e a produção em série, e impõem a necessidade de maior abastecimento de matérias-primas e de novos mercados de consumidores de manufaturados (Symrecsanyi, 1986).

Um outro fator que explica a generalização do uso automóvel associa-se à sensação de liberdade espacial que proporciona, ao superar com vantagens as formas de circulação existentes no tempo das cidades dos "andarilhos" ou dos "bondes", em face das imensas possibilidades de incremento da mobilidade que se abriam, o que estimulava a imaginação humana e a veiculação de símbolos de status social, conforto pessoal e familiar.

Em certa medida, outro fator relevante nessa discussão diz respeito à própria formação e desenvolvimento do estado capitalista moderno, fundamento do surgimento de nações politicamente fortes, de interesses transcontinentais, com grandes exércitos e marinhas de guerra a resguardar seus interesses. Ao protecionismo dos mercados, incluía-se a proteção militar de domínios territoriais, na medida em que as fronteiras e áreas de influência das nações eram ampliadas pelos continentes e oceanos. ${ }^{11}$

\footnotetext{
${ }^{11}$ O capitalismo não se internacionalizou repentinamente, como bem observa Soja (1993). Em princípio, o capitalismo mercantil, através do comércio de mercadorias, funcionou durante séculos para extrair superlucros no mundo inteiro. Nesse processo, os investimentos britânicos cumpriram um papel muito importante na implantação e difusão de novos padrões de consumo, destacadamente, no chamado setor terciário ou de serviços. Em primeiro lugar, contemplaram a infraestrutura de transportes, indispensável ao comércio exterior, ou seja, o trinômio ferrovias-portos-navegação marítima. Em seguida, mas não num plano secundário, eles se destinaram aos já citados serviços de utilidade pública,
}

Cadernos do Leste

Artigos Cientificos

Belo Horizonte, Edição Especial, 2000 a 2008 
A subordinação das economias dos países periféricos aos grandes países centrais apoiava-se na concentração e centralização dos capitais, processo inerente à transição do capitalismo concorrencial para o capitalismo oligopolista. Assim, quando o grande capital promoveu a expansão mundial de investimentos, as atividades de eletrificação já vinham sendo desenvolvidas na periferia capitalista, com a introdução de novos mercados, hábitos de consumo, a ponto de influir na qualidade da vida social (Ver Quadro). O período de expansão internacional das últimas décadas do século XIX, (quando, então, se configura a Era dos Trustes e Cartéis) ${ }^{36}$ se vale de uma dinâmica que combina mecanismos econômicos e financeiros que permitiram, inclusive, a chegada da Light no Brasil.

É inegável que a ruptura com o modal ferroviário e a adoção em larga escala e em pouco tempo do veículo leve, comprometeu as estruturas urbanas que se desenvolveram a partir de então (URB-AL n. 8, 2.000). Da histórica erradicação, desativação e abandono dos caminhos de ferro e sua quase eliminação na grande maioria das cidades americanas e brasileiras na primeira metade do século XX, restaram marcas que foram incorporadas aos espaços urbanos.

As diretrizes de desenvolvimento urbanístico adotadas geraram impactos inéditos sobre os mercados de terras urbanas, com a generalização do novo modal de transporte rodoviário. As espacialidades são alteradas e as cidades adquirem novas fisionomias. No bojo do processo de reestruturação, uma série de externalidades típicas da sociedade de consumo de massa atingia os residentes em áreas urbanas, que se alongavam por vias arteriais por centenas de quilômetros. As linhas de ônibus, responsáveis pelo transporte coletivo, venciam estas distâncias, mas separavam o local de trabalho do de moradia, exigindo sucessivos investimentos de ampliação e construção de novas vias, além de uma série de ações públicas mitigadoras da vertiginosa expansão das periferias urbanas que século XX conheceu.

isto é, aos sistemas de transportes urbanos, de iluminação pública, de águas e esgotos, de geração e distribuição de energia elétrica.

$20 \mathrm{Em}$ algumas nações, a burguesia pressionava as autoridades políticas para a criação de leis de proteção das fronteiras. A concorrência entre os empresários, muitas vezes feroz e desleal, motivou a criação de "leis antitrustes". Nos Estados Unidos, a Lei Sherman registra cinco ações judiciais antitrustes, embora quase cento e cinqüenta monopólios empresariais tenham se formado entre 1899 e 1901. Nas companhias ferroviárias eram comuns atentados contra comboios, destruição de trilhos, extorsões de dinheiro das cidades que ficavam à margem das estradas (História \& Energia, 1986).

Cadernos do Leste

Artigos Cientificos

Belo Horizonte, Edição Especial, 2000 a 2008 
"Longe de suplementar o transporte público eletrificado, o automóvel privado tornou-se, em grande parte, um seu desajeitado sucedâneo. Em vez de manter um complexo sistema de transportes, oferecendo alternativas de percursos e de velocidade, segundo a ocasião, a nova propagação suburbana tornou-se abjetamente dependente de uma única forma, o automóvel privado, cujo tamanho devorou a única comodidade de que se podia gabar o subúrbio: o espaço. Em lugar de edifícios erguidos num parque, temos agora edifícios levantados num estacionamento." (Mumford, 1965, p. 644).

O quadro de desolação e provisoriedade que a inusitada expansão urbana trazia impressionava. Talvez por isso, ainda em 1961, Jane Jacobs tenha publicado o Morte e vida de grandes cidades, obra na qual aborda a questão da necessidade dos automóveis nos subúrbios (com as externalidades que lhes são inerentes), em face do grande desperdício de solo urbano e do elevado índice de viagens baseadas no transporte individual.

"É comum o trânsito das vias expressas de Los Angeles parar por causa de acidentes. O problema é tão crônico, que os técnicos têm sugerido que os carros imobilizados sejam retirados com helicóptero. A verdade é que uma charrete a cavalo conseguia atravessar Los Angeles quase tão rápido em 1900 quanto um automóvel atualmente às 5 horas da tarde." (Jacobs, 2001, p. 394).

\section{5- COMO A URBANIZAÇÃO DESPERTOU O INTERESSE DAS GRANDES CORPORAÇÕES}

Nas primeiras décadas do século XX, a circulação urbana para além dos limites das áreas centrais se fazia com a utilização dos bondes, o que favoreceu a extensão de subúrbios e periferias urbanas como até então não fora possível. Os sistemas de bondes recémimplantados cobriam as necessidades de deslocamentos a partir dos centros urbanos, permitindo a um número cada vez maior de trabalhadores viver fora do centro comercial, onde localizavam seus empregos. A vida nos subúrbio tornou-se um fato consumado nos EUA: um em cada seis americanos vivia em subúrbios nas últimas décadas do século XIX (Rybczynski, 1995).

As cidades, até a primeira década do século XX, geralmente ostentavam uma pista central nas vias, que era reservada aos bondes. Os automóveis tinham de sair do caminho, era essa a condição quando a taxa de motorização ainda era muito baixa. Contudo, já em 1922,

Cadernos do Leste

Artigos Científicos

Belo Horizonte, Edição Especial, 2000 a 2008 
um em cada dez americanos já possuía carro. Os demais usavam o bondes e um certo percentual de trabalhadores que fazia seus deslocamentos a pé.

De toda a forma, a formidável expansão das atividades industriais e comerciais ao lado de um vigoroso crescimento demográfico lastreado pela imigração em larga escala em várias cidades americanas despertaram os interesses das corporações vinculadas ao aço, borracha, cimento e petróleo, setores estes em fase de afirmação e reestruturação diante da disseminação das novas tecnologias do fim do século XIX. A conjunção desses interesses resultou numa combinação bem-sucedida que iria impactar a economia industrial e alterar profundamente a fisionomia das cidades. Alfred Sloan, presidente da General Motors (GM) entre 1923-1956, concluiu que aquele momento caracterizou-se como um marco para a produção industrial. Afirmou, naquela ocasião:

"Esta é uma grande oportunidade. Podemos fazer com que esses 90\% do mercado (usuários de bonde) passem a usar carros. Se pudermos eliminar o bonde, criaremos um mercado novo para os nossos carros. Caso contrário, as vendas da GM continuarão como estão.” (Documentário - GNT Especial: Taken For a Ride, 1996).

A estratégia de mercado da corporação, que viria se tornar a maior do mundo, parecia clara: substituir os bondes e motorizar as principais cidades do país. Entendiam que, com a saída dos bondes desobstruía-se o espaço urbano e os que não quisesse andar de ônibus poderiam se tornar consumidores de automóveis.

A General Motors comprou a maior empresa de transporte urbano do país, a OMNIBUS, e o maior fabricante de ônibus, a YELLOW. De posse desses trunfos entrou no mercado de Manhattan, comprou ações da rede ferroviária de New York e, entre 1926 e 1936, conseguiu sucatear o sistema ferroviário.

Ao acenar com o novo ideal de liberdade de circulação, só possível mediante o emprego dos automotores, a GM influiu diretamente na mudança de hábito dos usuários e consumidores. Motorizou Manhattan, implantou linhas regulares de ônibus nas avenidas 8 e 9 e anunciou em todo o país que o uso do transporte rodoviário era o acontecimento mais importante na história dos transportes públicos. Em meados dos anos 30, vendia a idéia de modernização e difundia a tendência antitrilhos. Determinada em dar continuar o Cadernos do Leste 
desmantelamento do transporte ferroviário, insistia na ideia de novidade, liberdade e diversificação dos trajetos dos usuários de ônibus.

Em Los Angeles, os bondes, gradativamente, deixam de gerar lucros. Diante disso, não foi difícil a sua erradicação em cerca de três meses pela Fitzgerald’s Operation Manager. A empresa, ao associar seus negócios no setor de transporte com os ganhos no mercado imobiliário (ao disponibilizar terras para a expansão urbana) tornou-se milionária.

$\mathrm{Na}$ verdade, boa parte das empresas vinculadas aos bondes não extinguiu o serviço, mas diminuiu drasticamente sua oferta. Antes os veículos passavam a cada 10 minutos, depois, esse intervalo de tempo chegou a 30 minutos. Isto porque os empresários de ônibus, donos agora do serviço de bondes, tornavam o serviço menos atraente, aumentando as passagens o que afugentava usuários. Os lucros forçosamente teriam de reduzir e a desistência do negócio se afigurava "natural". Com isso, as empresas de bondes demitiram seus funcionários, tornados ociosos, ainda que muitos deles, pela idade, se viram compelidos a se aposentarem.

Efetivamente, foi a partir de 1930, e durante as três décadas seguintes, que as cidades americanas erradicaram os bondes, demoliram as estações de trem e construíram novas linhas de metrô e vias expressas. Berman (1994) afirma que as construções nos arredores de New York, implantadas por Robert Moses, serviram de ensaio para a reconstrução infinitamente maior de toda a tessitura espacial dos EUA após a Segunda Guerra Mundial, traduzidas em duas grandes forças motrizes: o multibilionário Programa Rodoviário Federal e as vastas iniciativas habitacionais da Administração Federal da Habitação. Essa nova ordem integrou o conjunto da nação num fluxo unificado cuja força vital vinha do automóvel.

A National City Lines (NCL) cresceu rapidamente e, em 1946, controlava a rede de transportes públicos em mais de 83 cidades $^{12}$. Nesse ano, o comandante Edwin J. Quimby, pessoa influente e com talento para investigação financeira, resolveu formular uma denúncia

\footnotetext{
12 No período da guerra, em decorrência da expansão demográfica anterior e do crescimento físico das cidades americanas, muitas delas vieram a enfrentar um impasse colocado pelo forte incremento do uso do transporte urbano sobre trilhos. Não obstante a atuação da NCL, o transporte de bondes vivia o seu apogeu em termos de demanda. Mas seu uso excessivo comprometeu os trilhos e deixou os bondes danificados. Era um momento de escolha: reconstruir o sistema de bondes ou deixá-lo morrer.
}

Cadernos do Leste

Artigos Cientificos

Belo Horizonte, Edição Especial, 2000 a 2008 
ao prefeito de New York, e, simultaneamente, repassá-la a centenas de pessoas influentes de diversas cidades. Acusava a GM de ter planejado uma campanha cujo objetivo era acabar com o sistema de bondes. Sua carta, de 33 páginas, continha detalhes surpreendentes. Revelava que a corporação tentava sucatear a rede de transportes urbanos e alertava sobre a impossibilidade de sua reativação, caso isso viesse a acontecer. Além disso, acrescentava algumas indagações: "Quais empresas estavam por trás disso?” E, ainda, "por que elas desejavam destruir importantes linhas ferroviárias?” Essas denúncias ficaram conhecidas como o "estranho caso de Quimby" (Queer case of Quimby). No momento em que o macartismo dava seus primeiros passos, Ross Schram, ao relatar o fato, considera que Quimby aproveitou-se da liberdade de expressão existente, "para alimentar os radicais e os loucos que se espalham feito erva daninha pelos EUA", conforme mostra texto do documentário da GNT: Taken For a Ride, 1996.

O esforço de Quimby não foi capaz de deter a ação da National City Lines, mas cumpriu um papel: o segredo havia sido revelado. Nesse mesmo ano, o Departamento de Justiça deu início a uma investigação antitruste na National City Lines, na General Motors e em outros investidores. Os advogados do caso afirmaram que não havia dúvidas de que os réus conspiravam a favor da destruição do sistema de bondes. Todavia, como não havia uma lei antitruste que contemplasse a proteção ao sistema de bondes, o único modo de incriminálos seria acompanhar suas ações. Com a consolidação das investigações, a NCL e a GM são indiciadas e culpabilizados por atuarem na monopolização da rede de transportes públicos. O Departamento de Justiça Americano passaria os próximos 25 anos tentando limitar a influência da GM nos transportes, principalmente por meio da acusação da prática de monopólio.

Mesmo assim, os anos do pós-guerra representaram momentos gloriosos para a indústria automobilística e seus executivos. Um expressivo contingente militar, após 15 anos de depressão e guerra, retornou aos EUA com recursos financeiros. Eram pessoas ansiosas para retomar suas vidas e fazer algum empreendimento. O Governo Federal subsidiava 
hipotecas para a construção de casas e estimulava a extensão das cidades rumo aos subúrbios. O sonho da classe média americana tornava-se realidade: a cada nova casa um automóvel.

O automobilismo, modelo adotado em vários países (como o Brasil), não se reproduziu com a mesma intensidade na Europa e no Japão, porquanto se investiu na reconstrução do sistema de bondes e o transporte sobre trilhos continua valorizado até os dias de hoje. Nos EUA, no entanto, as empresas de transporte, de caráter privado, resistiram aos custos de sua recuperação. A população pressionou para que os municípios assumissem e aprimorassem o sistema, mas a luta foi em vão. A NCL representava uma saída fácil e barata. Em todo o país, outras empresas adotavam essa alternativa. A eliminação dos bondes e sua substituição por ônibus parecia uma necessidade para se evitar um colapso financeiro e era uma questão de tempo. $^{13}$

Os interesses em disputas eram tão organizados, que em Baltimore, na Filadélfia e em Los Angeles, chegou-se a atear fogo em centenas de bondes. A mensagem era clara: os bondes eram desnecessários, não precisavam mais existir, pois os ônibus cumpriam bem o seu papel com inegáveis vantagens sobre os lentos bondes. Enfim, as corporações do aço, cimento, borracha e petróleo haviam vencido a batalha.

John D. Rockefeller e Henry M. Flagler (da Rockefeller e Standard Oil Company), ${ }^{38}$ tornaram-se os dois expoentes da indústria petrolífera a partir da obtenção de importantes concessões no transporte e venda de grandes quantidades de petróleo. A Standard Oil aumentou sua participação na indústria petrolífera de $10 \%$ para $20 \%$. Os dois gigantes, por meio de manobras intrincadas e sofisticadas, acumularam imenso poder e contaminaram as possibilidades de sucesso das companhias rivais (Hunt \& Sherman, 1982).

\footnotetext{
${ }^{13}$ Chegou a ser criada uma frente unificada pela manutenção dos bondes, mas, aos poucos, os bondes cederam lugar aos ônibus. A Public Utilities Comission deu à Pacific Electric o direito de usar ônibus em vez de bondes em suas linhas no subúrbio. Num prazo de 3 a 6 meses, os bondes deixaram de ser usados. No fim de dezembro de 1957, só restavam 3 linhas de bondes no centro da cidade de Los Angeles e 14 em toda a cidade.

${ }^{38}$ A Standard Oil Company de Ohio - razão social da sociedade criada por John D. Rockefeller e Henry M. Flagler, em 1870 - conseguiu imprensar contra a parede vários concorrentes e estabelecer monopólios regionais. Nessa década, apenas nove anos após a sua incorporação, a Standard Oil controlava entre 90\% e 95\% da produção nacional de petróleo refinada.
}

Cadernos do Leste

Artigos Cientificos

Belo Horizonte, Edição Especial, 2000 a 2008 
Breve súmula da expansão da indústria automobilística até 1970

\begin{tabular}{|c|c|}
\hline Ano & atos Marcantes \\
\hline 1903 & $\begin{array}{l}\text { riação da Ford Motor Company, em Detroit, com Henry Ford (1863-1947) como } \\
\text { ice-presidente e engenheiro-chefe. Em } 1908 \text { é lançado o Fort T }\end{array}$ \\
\hline 1908 & $\begin{array}{l}\text { W. C. Durand cria a General Motors mediante fusão da Buick, Oldsmobile, } \\
\text { Cadillac, Oakland. }\end{array}$ \\
\hline 1911 & W. Taylor (1856-1915) publica The principles of scientific management. \\
\hline 1913 & $\begin{array}{l}\text { ord aplica na indústria do automóvel a linha de montagem em cadeia (moving } \\
\text { ssembly line) }\end{array}$ \\
\hline 1914 & $\begin{array}{l}\text { Ford reduz a jornada de trabalho de } 9 \text { para } 8 \text { horas e estabelece o salário mínimo } \\
\text { de cinco dólares / dia (o dobro do que se praticava na indústria americana). }\end{array}$ \\
\hline 1927 & $\begin{array}{l}\text { A Volvo produz, com base no princípio da linha de montagem, automóveis e } \\
\text { depois de caminhões (1928) e de autocarros (1931). Mas a indústria americana é } \\
\text { dominada pelos três grandes: Ford, General Motors e Chrysler ( } 75 \% \text { das vendas). }\end{array}$ \\
\hline 1929 & $\begin{array}{l}\text { Início da Grande Depressão, no momento em que a indústria automobilística } \\
\text { produzia mais de } 5,3 \text { milhões de unidades. }\end{array}$ \\
\hline 1935 & $\begin{array}{l}\text { Suécia: Através de um processo de crescimento rápido (aquisição de firmas } \\
\text { fornecedoras, expansão do mercado interno, etc.), a Volvo torna-se uma empresa } \\
\text { independente }\end{array}$ \\
\hline 1941 & $\begin{array}{l}\text { ado norte-americano (47\%), à frente da Chrysler } \\
\text { ão de carros cai em função da mobilização exigida } \\
\text { roduz o célebre bombardeiro B-24. }\end{array}$ \\
\hline $1959 / 60$ & $\begin{array}{l}\text { Aumenta a competição com os norte-americanos, com o início da produção dos } \\
\text { carros pequenos. Os construtores europeus já detêm 10\% do mercado (com } \\
\text { destaque para os alemães da Volkswagen, os japoneses da Toyota, Datsun e } \\
\text { Honda, os suecos da Volvo, entre outros. Em } 1960 \text { é criado nos EUA o National } \\
\text { Highway Safety Bureau e os fabricantes se vêem diante de crescentes exigências de } \\
\text { segurança. }\end{array}$ \\
\hline 1965 & $\begin{array}{l}\text { Começa a deslocalização da indústria de automóvel americana (Ford e GM), } \\
\text { quando o Japão caminha para se tornar o primeiro produtor mundial de } \\
\text { automóveis. A produção do Japão passa de } 18.500 \text { unidades em 1950, para } 165 \text { mil } \\
\text { em 1960, 3,1milhões em } 1970 \text { e mais de } 7,1 \text { milhões em } 1983 \text { (em 1980, já era } \\
\text { considerado o primeiro produtor mundial de automóveis) }\end{array}$ \\
\hline 1970 & $\begin{array}{l}\text { Instala-se o debate sobre poluição do ar nos EUA. Os carros respondiam pela } \\
\text { emissão de } 84 \text { dos } 140 \text { milhões de toneladas de poluentes (hidrocarbonetos, } \\
\text { monóxido de carbono, etc.) a cada ano. Sob a pressão da opinião pública e dos } \\
\text { movimentos de defesa do ambiente, registram-se as primeiras preocupações do } \\
\text { poder político, no tempo do presidente Nixon, em relação à poluição do } \\
\text { automóvel. }\end{array}$ \\
\hline
\end{tabular}

Fontes: Volvo Group (2003); Berggren (2000); Lewis (1989); Ortsman (1978)

Cadernos do Leste

Artigos Científicos

Belo Horizonte, Edição Especial, 2000 a 2008 


\section{REFERÊNCIAS BIBLIOGRÁFICAS}

AGLIETTA, Michel. Regulacion y crisis del capitalismo. La experiência de los Estados Unidos. México: Siglo Veintuno Editores, S. A. de c.v. , 1976.

BERMAN, Marshall. Tudo que é sólido desmancha no ar. A aventura da modernidade. São Paulo: Editora Schwarcz Ltda, 1994.

BIHR, Alain. Da grande noite à alternativa. O movimento operário europeu em crise. São Paulo: Jinkings Editores Associados Ltda, 1999.

FAULKNER, Harold Underwood. História económica de los Estados Unidos. Tradução especial - 5a edição. Buenos Aires: Editorial Nova, 1956.

GALBRAITH, John Kenneth. Contando vantagem. Minhas histórias com Roosevelt, Truman, Kennedy e outros. TRio de Janeiro, São Paulo: Editora Record, 2000.

HALL, Peter. Cidades do amanhã. São Paulo: Editora Perspectiva, 1988. p. 57-145, 327-403.

HARVEY, David. Condição pós-moderna: uma pesquisa sobre as origens da mudança cultural. São Paulo: Editora Loyola, 1993.

HEILBRONER, Robert L. A formação da sociedade econômica. Tradução de Ivo Barroso. 3. ed. Rio de Janeiro: Zahar, 1974. p. 183-184.

HOBSBAWM, Eric J. A era do capital - 1848-1875. São Paulo: Paz e Terra, 2002.

HOBSBAWM, Eric J. A era dos extremos - O breve século XX, 1914-1991. Tradução de Marcos Santarrita. São Paulo: Companhia das Letras, 2000.

JACOBS, Jane. Morte e vida de grandes cidades. São Paulo: Martins Fontes, 2001.

LIPIETZ, Alain. As transformações na divisão internacional do trabalho: considerações metodológicas a esboço de teorização. In: Espaço e Debates. Ano IV, n. 12, 1984.

LUDD, Ned (Org.). Apocalipse motorizado. A tirania do automóvel em um planeta poluído. Tradução de Leo Vinicius. São Paulo: Conrad Editora do Brasil, 2004. (Coleção Baderna).

MARX, Karl. El capital. 8ª ed. México: Fondo de Cultura Económica, 1973.

Cadernos do Leste

Artigos Científicos

Belo Horizonte, Edição Especial, 2000 a 2008 
MARTINS, Sérgio M. E. UNIVERSIDADE E DEMOCRACIA: Proposições para uma pósgraduação crítica, 2003. Artigo não publicado.

MUMFORD, Lewis. A cidade na história. Belo Horizonte: Itatiaia, 1965.

NETO, Benedito Rodrigues de Moraes. Marx, Taylor, Ford - as forças produtivas em discussão. São Paulo: Editora Brasiliense S. A., 1991.

OKUBARO, Jorge J. O automóvel, um condenado? São Paulo: Editora SENAC São Paulo, 2001.

OWEN, Wilfred. Estratégia para os transportes. Tradução de David Hastings. São Paulo: Livraria Pioneira Editora, 1975.

RYBCZYNSKI, Witold. Vida nas Cidades: expectativas urbanas no novo mundo. Rio de Janeiro/São Paulo: Record, 1995.

SGUIGLIA, Eduardo. Fordlândia (romance). São Paulo: Editora Iluminuras Ltda, 1997.

SOJA, Edward W. Geografias pós-modernas: a reafirmação do espaço na teoria social crítica. Rio de Janeiro: Jorge Zahar Editor, 1993.

SZMRECSÁNYI, Tamás. In: HISTÓRIA \& ENERGIA. A chegada da LIGHT. Divisão da Biblioteca da Eletropaulo, 1986. Ficha Cartográfica, p. 6 a 19.

TOPALOV, Christian. Las contradiciones de la urbanizacion capitalista: algunos elementos para su analisi. México: Editorial Edicol México, 1979.

URB-AL, no 8/2000 - CONGRESSO DE LANÇAMENTO DA REDE URB-AL, nº 8, de 18 a 20/10/2000, Stuttgard. Controle da Mobilidade Urbana. Relatório BHTRANS.

\section{PERIÓDICOS, JORNAIS, REVISTAS e VÍDEOS}

DOCUMENTÁRIO da GNT especial - Taken For a Ride, tradução e legenda: GLOBOSAT, Copyright de Jim Klein e Martha Olson, 1996.

HISTÓRIA \& ENERGIA. A chegada da LIGHT. São Paulo, Departamento de Patrimônio Histórico da Eletropaulo - ELETRICIDADE DE SÃO PAULO, 1986. 80 p. INTERNET

Cadernos do Leste

Artigos Cientificos

Belo Horizonte, Edição Especial, 2000 a 2008 
HUNT \& SHERMAN. História do pensamento econômico. Petrópolis: Vozes, 1982. p. 123124) http://www.musicstuff.hpg.ig.com.br/imperialismo.html - em 28 de fevereiro de 2004. 